Narrative Practice may Foster Comfort but not Enhance Cognition in Adult Witness Interviews About a Mock Sexual Assault

Sonja P. Brubacher ${ }^{1}$, Stefanie J. Sharman ${ }^{2}$, Nina J. Westera ${ }^{3 \dagger}$, Hamida Zekiroski ${ }^{4}$, Meaghan C. Danby ${ }^{5}, \&$ Martine B. Powell ${ }^{6}$

1. Centre for Investigative Interviewing, Griffith Criminology Institute, Griffith University, QLD, Australia. ORCID: 0000-0002-2422-9913 LinkedIn: sonja-brubacher-66345845

2. School of Psychology, Deakin University, VIC, Australia. ORCID: 0000-0002-0635047X

3. Centre for Investigative Interviewing, Griffith Criminology Institute, Griffith University, QLD, Australia. ORCID: 0000-0002-8594-3686 'Deceased May 25, 2017

4. Centre for Investigative Interviewing, Griffith Criminology Institute, Griffith University, QLD, Australia. ORCID: 0000-0001-6018-4858

5. School of Psychology, Deakin University, VIC, Australia. ORCID: 0000-0001-70607121

6. Centre for Investigative Interviewing, Griffith Criminology Institute, Griffith University, QLD, Australia. ORCID: 0000-0001-5092-1308

Brubacher, S. P., Sharman, S. J., Westera, N. J., Zekiroski, H., Danby, M. C., \& Powell, M. B. (2020). Narrative practice may foster comfort but not enhance cognition in adult witness interviews about a mock sexual assault. Journal of Forensic Psychiatry and Psychology. Accepted July 16, 2020. doi: 10.1080/14789949.2020.1799056.

Author Note: Correspondence and reprint requests should be sent to Sonja P. Brubacher, s.brubacher@griffith.edu.au Centre for Investigative Interviewing, Griffith Criminology Institute, Griffith University, 176 Messines Ridge Road, Mount Gravatt, 4122, QLD, Australia.

Declaration of interest statement: The authors declare no conflicts of interest.

Data availability statement: The data that support the findings of this study are available from the corresponding author upon reasonable request.

Acknowledgements: This research was partially funded by a Discovery Early Career Researcher Award (DECRA) Australian Research Council (ARC) grant to NJW. 


\begin{abstract}
The present study tested the effectiveness of narrative practice on adult witnesses' reports about a mock sexual assault. Narrative practice is a rapport-building activity that involves recounting a neutral or pleasant event prior to discussing the target topic. Engaging in narrative practice tends to enhance children's reporting, but its utility with adults is unknown. Adults $(n=62) 18$ - to 62-years-old viewed a 7-minute video of a mock sexual assault and then were questioned with an open-ended protocol that began with narrative practice or not. Results showed that narrative practice did not appear to aid memory retrieval but may have increased comfort for some participants. Findings are discussed with regard to interviewing practice.
\end{abstract}

Keywords: investigative interviewing; adult witness; narrative practice; episodic memory training; eyewitness testimony 


\section{Narrative Practice may Foster Comfort but not Enhance Cognition in Adult Witness Interviews About a Mock Sexual Assault}

Sexual assault and other vulnerable victims may need time at the outset of the interview to get settled and decide whether they are comfortable sharing intimate details (Campbell, 2008). Interview components may affect the willingness of victims and witnesses of traumatic events to recall and share their memories, such as whether or not interviewers take time to build rapport (Patterson, 2011). For example, some adolescent interviewees wished for more time to get settled and talk about other, non-confronting topics before police raised the sensitive subject of their sexual assault (Greeson et al., 2014). When the interview process supports victims to give a useful early account, it can help to protect them or reduce the likelihood of statement retraction (Nelson, 2012; Westera \& Powell, 2017). The better the quality of early interviews, the more likely important elements for case progression can be achieved.

Narrative practice is a rapport building activity that gives children experience with the interview process, including responding to open-ended prompts about innocuous topics and gives the interviewer experience with the child (e.g., identifying potential barriers, communication style). It has been shown to increase the amount of information children produce about subsequently discussed substantive topics (e.g., Price et al., 2013; Sternberg et al., 1997; Whiting \& Price, 2017). Narrative practice could serve to increase comfort, and a comfortable witness can give a more complete and accurate account (e.g., Vallano \& Schreiber Compo, 2011).

To our knowledge, narrative practice has not been tested in published research with adults but, to the extent that it settles a witness, it may have benefits. It is possible that, like children, adults are unclear about the type and amount of detail expected of them. This notion is supported by research where some adult participants read a detailed model statement (a 
true account of a surprise helicopter flight) before writing their own true and false statements about negative events. Adults who read the model statement produced longer accounts than those who did not read it (Bogaard et al., 2014).

In the present study, adult participants watched a video of a mock sexual assault and were then interviewed with open-ended interviews that commenced with narrative practice or not. We predicted that participants who engaged in narrative practice (compared to those who did not) would report more details from the video and would feel more comfortable with the interview.

\section{Method}

\section{Participants}

Participants responded to advertisements placed around a university campus and online. Sixty-two adults (18-62 years; $M=30.11, S D=12.16 ; 34$ females) signed informed consent forms, participated, and were compensated with a gift card (AUD \$20). They had a range of education: high school (35.9\%), associate degree or diploma (15.2\%), bachelor's degree (25.0\%), and postgraduate degree (23.9\%). [Blinded] University granted approval for the study.

\section{Materials and Procedure}

Participants watched a 7 min video depicting an implied sexual assault of a client by a massage therapist, based on a reported case. After completing distractor puzzles for $12 \mathrm{~min}$, participants went to a second room for the interview. They were randomly and equally assigned to receive narrative practice or not, prior to discussing the video. One female interviewer, blind to the hypotheses of the study, conducted all interviews.

Interviews began with a short exchange to become acquainted. Then, control participants moved directly to the substantive interview phase, while participants in the narrative practice condition first discussed an unrelated event. Appropriate events were 
considered to be any recently experienced pleasant activity that the interviewee wanted to discuss. Narrative practice ranged from 2.28 to $6.72 \operatorname{mins}(M=4.17, S D=1.23)$, and consisted only of open-ended prompts.

The interviewer began the substantive interview phase with a simple invitation: "Now let's talk about the video you watched today. Tell me everything that happened in the video." She employed active listening strategies, such as nodding and giving minimal encouragers (e.g., "Mmmmm"), and delivered exclusively open-ended prompts. At the conclusion of the interview, participants in the practice condition answered one additional question about whether they thought that talking about a personal event before discussing the video was helpful. All interviews were transcribed verbatim.

\section{Coding and Reliability}

Participants' accounts were scored for forensically-relevant details from the witnessed video. Two authors created a list of possible details that participants could report $(\max .=83)$. Eleven were considered central to proving the elements of the offence (central details). All details could be scored as correct or incorrect. Any other errors (e.g., confabulations about things that never happened in the video) were combined with incorrect details; they were infrequent. Repeated details were counted when the participant reported any detail a subsequent time. Two research assistants (RAs) were trained to code the details using six randomly selected transcripts. After training, the RAs double coded 20 new transcripts for reliability. Inter-rater reliability was very good, with $82.2 \%$ agreement on scores.

Disagreements were resolved through discussion. The coders split the remainder of the coding evenly.

Thematic analysis (Braun \& Clarke, 2006) was used to code the qualitative narrative practice data. Categories were generated by one author and one RA reading the transcripts independently and generating themes until no new concepts were needed to capture the data. 
They came together and found that they agreed on the three main themes and six subthemes in Table 1, as well as primary categories for topic chosen and event recency. They collapsed any categories that overlapped (e.g., increases comfort and reduces anxiety were combined) and revisited the transcripts to check that the categories adequately captured the data. They named the categories and created operational definitions for them. A second author who had not been involved in the first stage of coding then doubled coded all qualitative data $(n=31)$, and the reliability of codes was assessed with Cohen's kappa. Responses about whether or not narrative practice was helpful fell into one of three categories: no, yes, ambiguous (kappa $=1.00)$, each with two subcategories $($ kappa $=.94)$. Topic chosen was categorized as: hobby, social activity, study-related, and travel $(\mathrm{kappa}=.96)$. Recency of the event included: past week, past month, past year, and +1 year $($ kappa $=.94)$. For each of the latter three variables, there was one disagreement, resolved by revisiting the coding and deciding which category was appropriate.

\section{Results}

\section{Preliminary Analyses}

Interview conditions were balanced for age and gender, $p s \geq .98$. Participants in the practice condition took longer to complete their interviews $\left(M_{\operatorname{mins}}=19.95, S D=5.99\right)$ than control participants $\left(M_{\text {mins }}=15.16, S D=10.02\right), t(60)=2.82, p=.026$, Cohen's d $=.59$, but no longer differed once narrative practice was subtracted $\left(M_{\operatorname{mins}}=15.77, S D=5.25\right), p=.76$. Thus, time spent discussing the video was equivalent.

\section{Effects of Interview Condition on Memory Performance}

A 2 (condition: practice, control) one-way MANOVA was not significant, Pillai's Trace $=.05, F(4,57)<1, p=.73, \eta_{p}{ }^{2}=.05$. Participants in both conditions reported the same number of correct details $\left(M_{\text {practice }}=32.61, S D=7.94 ; M_{\text {control }}=28.77, S D=9.77\right)$, central details $\left(M_{\text {practice }}=7.77, S D=1.56 ; M_{\text {control }}=7.32, S D=1.82\right)$, errors $\left(M_{\text {practice }}=3.03, S D=\right.$ 
$\left.1.76 ; M_{\text {control }}=2.84, S D=2.87\right)$, and repeated details $\left(M_{\text {practice }}=23.58, S D=13.33 ; M_{\text {control }}=\right.$ $19.06, S D=13.28)$.

\section{Practice Narrative Characteristics and Perceptions}

Two participants did not answer the narrative practice perception question. Of the remainder, 13 (45\%) did not find it helpful, nine (31\%) did, and seven (24\%) were unsure or ambivalent. Table 1 provides examples of the reasons they gave. Participants who did not find it helpful said they felt uncomfortable sharing personal information with a stranger, or they wanted to get straight to reporting about the video before they forgot information. Those who found it helpful talked about increased comfort and clearer expectations about the interview process. A few participants were simply unsure, but four were genuinely ambivalent; they reported that it did make them feel more comfortable/they enjoyed it, but they did not think it improved their memories.

Most participants $(n=28,90 \%)$ generated a topic for the practice narrative on their own. Seven talked about the last time they engaged in a hobby or extra-curricular activity. Four of those events were within the past week, one was a year earlier, and the timeframe for the other two were unclear. Twelve participants described a social activity and four talked about study-related events; these activities all occurred within a month of the interview. Eight described trips varying from one week to more than a year ago.

\section{Discussion}

Narrative practice did not affect the quality of adult witnesses' accounts of a mock sexual assault. Therefore, our data suggest that-at least for some types of events-narrative practice does not bolster or impair the ability to retrieve memories (e.g., bystander event at short delay). It improved the interview process for nearly a third of interviewees, but just under half did not find it helpful. 
If narrative practice gives victims and witnesses time to settle and become less anxious before giving their accounts, it should have benefits for memory (Vallano \& Schreiber Compo, 2011). However, if interviewees' emotional responses are minimal, they may perceive narrative practice as interfering with their ability to relay the details as soon as possible before they forget what they witnessed (e.g., police attending witnesses at the scene of an armed robbery). Our qualitative results support these conjectures. Participants who found practice helpful said it increased their comfort and understanding of the interview process. Most who did not find it helpful commented that they just wanted to get on to talking about the video because it was fresh in their minds. Two of the three participants who were uncomfortable did not want to share personal information with a stranger. Yet, sexual assault victims must do just that, and perhaps starting with personal, but less confronting, information would be helpful (e.g., Greeson et al., 2014). This notion remains to be tested. We chose to use a witnessed sexual assault as our to-be-remembered event, in the hope of (ethically) simulating some of the contextual factors that would affect victims' abilities to recount their experiences. Witte and colleagues (2017) found that $90 \%$ of surveyed students had witnessed at least one risky situation associated with sexual assault or dating violence, and some reported experiencing fear and secondary trauma.

Future research on the utility of narrative practice and other memory supports for an emotionally-laden event should address the present study's limitation of using a videotaped event. For example, the Trier Social Stress Test creates anxiety with a public speaking task (Kirschbaum et al.,1993). Although very different to experiencing a sexual assault, it might simulate some of the underlying mechanisms speculated to make narrative practice effective. If research could identify these factors, the conditions under which narrative practice is useful for adult interviewees may become clearer. Further, while the present sample did include a broad range of maximum education levels (the largest group being high school diploma), 
more research on this topic is needed with vulnerable populations (e.g., adults with cognitive impairment, communication difficulties, high trauma victims). These limitations can be conceptualized as positive implications for research in this area, as there is major scope for further inquiry.

In conclusion, our findings suggest narrative practice neither impairs nor benefits adults' memories for a witnessed event, and adults were generally split on their perceptions about its utility under these circumstances. The research highlights the importance of interviewers understanding the potential functions of narrative practice, considering them in relation to individual interviewees' needs and case circumstances, and collaborating with the interviewee on the interview process. Such a victim-centred approach would have positive implications for procedural justice (Patterson, 2011). Tentative implications for practical application arising from this research are that narrative practice may not be useful when adult witnesses appear prepared to talk, but it could be advantageous (and not harmful) when witnesses need time to settle. More research is needed to test these conclusions with an emotionally-laden, personally-experienced event. 


\section{References}

Bogaard, G., Meijer, E. H., \& Vrij, A. (2014). Using an example statement increases information but does not increase accuracy of CBCA, RM, and SCAN. Journal of Investigative Psychology and Offender Profiling, 11, 151-163. doi: 10.1002/jip.1409

Braun, V., \& Clarke, V. (2006). Using thematic analysis in psychology. Qualitative Research in Psychology, 3, 77-101. doi:10.1191/ 1478088706qp063oa

Campbell, R. (2008). The psychological impact of rape victims' experiences with the legal, medical, and mental health systems. American Psychologist, 68, 702-717. doi: 10.1037/0003-066X.63.8.702

Greeson, M. R., Campbell, R., \& Fehler-Cabral, G. (2014). Cold or caring? Adolescent sexual assault victims' perceptions of their interactions with the police. Violence and Victims, 29, 636-651. doi: 10.1891/0886-6708.VV-D-13-0003

Kirschbaum, C., Pirke, K. M., \& Hellhammer, D. H. (1993). The 'Trier Social Stress Test'-a tool for investigating psychobiological stress responses in a laboratory setting. Neuropsychobiology, 28, 76-81. doi: 10.1159/000119004

Nelson, E. L. (2012). Police controlled antecedents which significantly elevate prosecution and conviction rates in domestic violence cases. Criminology and Criminal Justice, 13, 526-551. doi:10.1177/1748895812462594

Patterson, D. (2011). The impact of detectives' manner of questioning on rape victims' disclosure. Violence Against Women, 17, 1349-1373. doi: /10.1177/1077801211434725

Price, H. L., Roberts, K. P., \& Collins, A. (2013). The quality of children's allegations of abuse in investigative interviews containing practice narratives. Journal of Applied Research in Memory and Cognition, 2, 1-6. doi: 10.1016/j.jarmac.2012.03.001

Sternberg, K. J., Lamb, M. E., Hershkowitz, I., Yudilevitch, L., Orbach, Y., Esplin, P. W., \& Hovav, M. (1997). Effects of introductory style on children's abilities to describe 
experiences of sexual abuse. Child Abuse \& Neglect, 21, 1133-1146. doi:10.1016/S0145-2134(97)00071-9

Vallano, J. P., \& Schreiber Compo, N. (2011). A comfortable witness is a good witness: Rapport-building and susceptibility to misinformation in an investigative mock-crime interview. Applied Cognitive Psychology, 25, 960-970. doi: 10.1002/acp.1789

Westera, N. J., \& Powell, M. B. (2017). Prosecutors' perceptions of how to improve the quality of evidence in domestic violence cases. Policing and Society, 27, 157-172. doi: $10.1080 / 10439463.2015 .1039002$

Whiting, B. F., \& Price, H. L. (2017). Practice narratives enhance children's memory reports. Psychology, Crime \& Law, 23, 730-747. doi: $10.1080 / 1068316 X .2017 .1324031$

Witte, T. H., Casper, D. M., Hackman, C. L., \& Mulla, M. M. (2017). Bystander interventions for sexual assault and dating violence on college campuses: Are we putting bystanders in harm's way? Journal of American College Health, 65, 149-157. doi: 10.1080/07448481.2016.1264407 
Table 1

Perceptions of Narrative Practice

Not helpful $n=13$

Discomfort $\quad$ Sharing personal details $n=2$

I did not feel comfortable talking about personal life events with a stranger.

- Memory challenges $n=1$

I forgot more details on my personal event than I would have thought considering it was only two weeks ago. It was quite embarrassing!

Irrelevance/ • Unnecessary $n=3$

Distraction I didn't find it necessary for me to talk about a personal experience because I was comfortable in the setting already.

- Memory decay $n=4$

Was keen to impart info about the video ASAP so as not to forget what I had seen.

\section{Helpful $n=9$}

Comfort $\quad$ To settle into the environment/warm-up to the interview $n=6$

It got me acquainted with what the interview style was like and what was expected of me.

Hearing my own voice and allowing myself to warm up to someone new prepared me to find words one the more formal-like interview process took place.

- To become comfortable (non-specific) $n=2$

It helped me feel comfortable in the interview and remember things.

- To become comfortable with a stranger $n=1$

It made a comfortable environment in terms of talking to someone you haven't really met before.

Other $\quad$ No reason provided $n=3$

\section{Ambiguous $n=7$}

Unsure $\quad n=3$

I'm not sure if it was helpful or not.

Ambivalent $n=4$

It can help make it (the interview) slightly more comfortable, but it didn't affect my ability to recount the details. 
Either way I wouldn't have minded. I guess it made me feel a bit more comfortable.

No, I personally felt it [negatively] affected my memory of the video. But I did enjoy talking about my personal event because it made me feel good. 